\title{
A Deficiency of Both Subunits of Pyruvate Dehydrogenase which is Not Expressed in Fibroblasts
}

\author{
DOUGLAS S. KERR, SUSAN A. BERRY, MARILYN M. LUSK, LAP HO, AND \\ MULCHAND S. PATEL \\ Departments of Pediatrics and Biochemistry, Case Western Reserve University School of Medicine, Cleveland, \\ Ohio 44106, and Department of Pediatrics, University of Minnesota School of Medicine, \\ Minneapolis, Minnesota 55455
}

\begin{abstract}
Pyruvate dehydrogenase complex (PDC) deficiency usually has been detected by decreased activity in cultured skin fibroblasts. We investigated two brothers in whom PDC activity was less than $10 \%$ of controls in lymphocytes but normal in skin fibroblasts. They both had abnormal neuromuscular development and lactic acidosis which was aggravated by ingestion of carbohydrate. One brother died at age $3 \mathrm{yr}$ and tissues were obtained at autopsy soon after death. The brain was swollen with diffuse acute hemorrhages but without the lesions characteristic of Leigh's disease. PDC activity was virtually undetectable in mitochondria or homogenates of liver, skeletal muscle, and heart, but was about $30 \%$ of controls in kidney. The activity of the first component $E_{1}$ was not detectable in mitochondria from liver, whereas the activities of the second and third components were normal; the activities of all components were normal in fibroblasts. Western immunoblot analysis showed absent to trace amounts of both the $E_{1} \alpha$ and $E_{1} \beta$ subunits in liver, skeletal muscle, and heart, with normal amounts of the second and third components. About one-fourth of control amounts of $E_{1} \alpha$ and $E_{1} \beta$ were present in kidney and normal levels were present in fibroblasts. PDC activity in lymphocytes from the mother was $35 \%$ of controls; she had normal PDC activity in her fibroblasts. PDC activity was normal in lymphocytes from the brothers' sister, father, and maternal grandparents and great-grandmother. The mode of inheritance was not established. In conclusion, PDC deficiency may not be detected in skin fibroblasts in some cases; the mechanism of variable tissue expression of $E_{1}$ remains to be delineated (Pediatr Res 24: 95-100, 1988)
\end{abstract}

\section{Abbreviations}

PDC, pyruvate dehydrogenase complex

$E_{1}$, first component of PDC (pyruvate dehydrogenase)

$\mathrm{E}_{2}$, second component of PDC (dihydrolipoamide acetyltransferase)

$E_{3}$, third component of PDC (dihydrolipoamide dehydrogenase)

SDS, sodium dodecyl sulfate

Received December 28, 1987; accepted March 7, 1988.

Correspondence and reprint requests Douglas S. Kerr, M.D., Department of Pediatrics, Rainbow Babies and Childrens Hospital, 2074 Abington Road, Cleveland, $\mathrm{OH} 44106$.

Supported by The national Institute of Arthritis, Diabetes, Digestive and Kidney Diseases, Grant AM-20478. L.H. is a predoctoral fellow supported by NIH Metabolism Training Grant AM-07319.
PDC deficiency is a potentially severe inborn error of energy metabolism, sometimes associated with devastating neurological consequences and death. More than 100 cases of PDC deficiency have been reported (1-3). Great variability has been observed in the clinical severity of this disorder, which is not correlated with the residual activity of PDC. Most measurements of PDC activity have been done with cultured skin fibroblasts. In a previously reported case of severe systemic PDC deficiency, we found that residual PDC activity was relatively greater in fibroblasts than in lymphocytes, liver, skeletal muscle, heart, kidney, or brain, suggesting the possibility that cultured skin fibroblasts may not accurately reflect the status of PDC in other tissues (4).

PDC is composed of multiple protein subunits that include three main catalytic enzymes and at least two regulatory proteins. The first enzyme, pyruvate dehydrogenase or $E_{1}$, catalyses the decarboxylation of pyruvate and consists of two nonidentical subunits, $\mathrm{E}_{1} \alpha$ and $\mathrm{E}_{1} \beta$. The second enzyme, dihydrolipoamide acetyltransferase or $E_{2}$, catalyses the transfer of the acetyl residue to coenzyme $\mathrm{A}$. The third enzyme. $\mathrm{E}_{3}$, is a flavoprotein common to all three $\alpha$-ketoacid dehydrogenase complexes which reoxidizes the lipoyl moiety of $\mathrm{E}_{2}$ and reduces NAD ${ }^{+}$. The regulatory subunits include a specific kinase, which phosphorylates $E_{1}$ rendering the complex inactive, and a phosphatase, which reactivates the complex. Most reported cases of PDC deficiency appear to involve the $E_{1}$ component (1-3). In two cases we have found nearly complete absence of immunoreactivity of both the $\alpha$ and $\beta$ subunits of $E_{1}(4,5)$. Both of these cases were associated with neuropathological findings characteristic of Leigh's encephalomyelopathy.

The family described herein represents a variation in tissuespecific expression of systemic PDC deficiency affecting both subunits of $E_{1}$. Although the clinical outcome was equally severe as the previously reported cases, the neuropathological findings of Leigh's disease were not present and the activity of PDC was completely normal in skin fibroblasts. If PDC activity had not been found initially to be very low in lymphocytes, this defect could easily have gone unrecognized.

\section{METHODS}

Human subjects. Blood and tissue specimens were obtained from the patients and controls with informed consent according to protocols approved by the Institutional Review Board of University Hospitals of Cleveland. Blood samples for preparation of control lymphocytes were obtained from adult volunteers. Control skin fibroblasts were obtained from cell lines derived from infants and children forwarded from a number of laboratories. Tissue samples used for control data were obtained at autopsy (liver, muscle, kidney, and heart) or by biopsy (liver, 
muscle) from children without PDC deficiency who were investigated for diagnosis of other defects associated with lactic acidosis or abnormal fatty acid oxidation.

Preparation of lymphocytes, fibroblasts, and mitochondria. Lymphocytes were isolated from anticoagulated whole blood by the Ficoll-Paque method (6) and resuspended in phosphatebuffered saline for assay (4). Skin fibroblasts were subcultured until confluent, harvested with trypsin, and washed in phosphatebuffered saline for assay (4). Mitochondria were prepared from samples of liver and skeletal muscle obtained within $1 \mathrm{~h}$ of death by homogenization in mannitol-sucrose-morpholinopropane sulfonic acid-EDTA buffer and standard techniques of differential centrifugation $(4,7)$. Pieces of whole tissue frozen immediately after autopsy or biopsy were homogenized just before each assay.

Enzyme assays. PDC activity was measured by decarboxylation of $\left[1-{ }^{14} \mathrm{C}\right]$ pyruvate, using a minor modification of the method of Sheu et al. $(4,8)$. Intact cells or mitochondria were preincubated in the presence of buffer alone (untreated), dichloroacetate (activated), or fluoride (inactivated) before addition to the assay mixture. Thiamin pyrophosphate and coenzyme A were omitted from blank tubes. Each assay included four reaction tubes and four blanks for each of the preincubation conditions. Control samples were prepared simultaneously with samples from the patient and included in each assay. Frozen tissues were homogenized in 20 volumes of a buffer ( $\mathrm{pH} 7.4$ ) containing 80 $\mathrm{mM} \mathrm{KCl}, 50 \mathrm{mM}$ morpholinopropane sulfonic acid, $2 \mathrm{mM}$ $\mathrm{MgCl}_{2}$, and $0.5 \mathrm{mM}$ EDTA. These samples were assayed without preincubation, except where indicated homogenized frozen liver was preincubated for $15 \mathrm{~min}$ in the same dichloroacetate activation buffer used for intact cells (8) with addition of $0.5 \mu \mathrm{g} / \mathrm{ml}$ leupeptin, $0.4 \mathrm{mM}$ phenylmethylsulphonyl fluoride, and $0.7 \mathrm{U} /$ $\mathrm{ml}$ of purified $\mathrm{E}_{1}$ phosphatase, kindly provided by Dr. Thomas Roche (Kansas State University, Manhattan, KS).

The $E_{1}$ component of PDC was assayed in the same way without addition of coenzyme $\mathrm{A}$ and $\mathrm{NAD}^{+}$in the presence of ferricyanide (4). $E_{2}$ was assayed by acetylation of reduced lipoamide with $\left[1-{ }^{14} \mathrm{C}\right]$ acetyl-CoA, omitting addition of enzyme for blanks $(4,9)$. $E_{3}$ was assayed spectrophotometrically by reduction of $\mathrm{NAD}^{+}$in the presence of reduced lipoamide (9). Pyruvate carboxylase and phosphoenolpyruvate carboxykinase were measured by fixation of ${ }^{14} \mathrm{CO}_{2}$ and conversion of the oxalacetate formed to citrate or malate, respectively, as previously described (10). Protein was measured by the method of Lowry et al. (11) using bovine serum albumin as a standard.

Immunoassays. PDC components were analyzed by the Western blot method $(4,5)$. Frozen tissues were homogenized in potassium phosphate buffer with Triton X-100, sonicated, and centrifuged. Aliquots of the supernatant were denatured by boiling with dithiothreitol and SDS. The protein extracts were separated by electrophoresis in SDS-polyacrylamide gels (12) and electrotransferred onto nylon-based membranes. The membranes were then blocked by preincubation with bovine serum albumin, incubated with specific antisera followed by $\left[{ }^{125} \mathrm{I}\right]$ protein $\mathrm{A}$, and visualized by exposing to $\mathrm{x}$-ray film. The preparation of specific rabbit antisera against the individual PDC components $\left(E_{1}, E_{2}\right.$, and $\left.E_{3}\right)$ was previously described $(4,5)$.

\section{CASE REPORT}

$\mathrm{CH}$ was the product of an uncomplicated full-term pregnancy and delivery (birth weight $3120 \mathrm{~g}$ ), and was apparently normal until age 5 months when he was hospitalized after sudden onset of weakness and respiratory insufficiency, requiring ventilatory support. Serum lactate was $4.6 \mathrm{mM}$ (normal $0.5-2.0 \mathrm{mM}$ ) and cerebrospinal fluid lactate was $10.8 \mathrm{mM}$ (normal $<3.0 \mathrm{mM}$ ). He improved but had onset of seizures several months later and continued to have intermittent episodes of weakness. The hereditary nature of his disorder was suspected when a younger brother, JH, presented with a similar condition (see below).
Reevaluation at age 2 yr showed persistently elevated blood lactate $(2.0-10.0 \mathrm{mM})$ and pyruvate $(0.12-0.16 \mathrm{mM}$; normal $0.03-0.10 \mathrm{mM})$, with a normal lactate/pyruvate ratio $(15-20$; normal 10-20). Urine organic acids showed only increased lactate and plasma amino acids showed only increased alanine. Plasma ammonia, free and total carnitine, and biotinidase were normal. Intravenous administration of glucose during an episode resulted in a rapid decompensation necessitating ventilator support. He responded well to treatment with a high fat, low carbohydrate diet; a brief challenge with dietary carbohydrate resulted in exacerbation of weakness. Withdrawal of thiamin that had been added to his treatment did not result in clinical change. He continued to have persistent weakness, ataxia, hypotonia, and areflexia which were worse in the mornings and also with minor illnesses. The fat content of his diet was gradually increased to $86 \%$ of energy, with $8 \%$ as protein and $6 \%$ as carbohydrate. Linear growth and weight were normal, but he was microcephalic. His development was delayed; he spoke only three to five words and could not stand alone. During his terminal illness he had recurrent episodes of respiratory insufficiency requiring ventilator support. Arterial lactate remained very high (up to $18 \mathrm{mM}$ ) with a normal lactate/pyruvate ratio $(6-6.5)$. Administration of dichloroacetate, $50 \mathrm{mg} / \mathrm{kg}$ intravenously, did not help. Serum carnitine was now very low (free, 2.6, and total, $5.8 \mu \mathrm{M}$; normal: $37 \pm 9$ and $46 \pm 9$, mean $\pm \mathrm{SD}$, respectively) and oral L-carnitine was administered. Echo- and electrocardiograms were normal. One week before death a head CT scan with contrast media appeared normal. He then again became weaker, and after a difficult intubation deteriorated rapidly, becoming hyper- and hypotensive without spontaneous respiration. A head MRI scan showed high density areas in the basal ganglia and brain stem, consistent with hemorrhagic injury. Two EEG showed electrocerebral silence.

Electron microscopy of a muscle biopsy (before L-carnitine administration) showed some areas of grouping of both major fiber types consistent with denervation/renervation, and mild lipid storage. Mitochondria appeared normal in structure and size. On autopsy mild hepatosplenomegaly was noted, but microscopic examination of liver showed normal lobular architecture without excess fat collection in hepatocytes. There was also no evidence of lipid deposition in skeletal muscle. The heart appeared very mildly hypertrophic, and myocardial cells showed some central cytoplasmic clearing. The brain was diffusely very swollen, soft, and showed central herniation. There was extensive recent hemorrhagic infarction of the basal ganglia, thalamus, midbrain, tegmentum of the pons, and brainstem. There were no discernible subacute necrotizing lesions in the gray matter, mammilary bodies, midbrain, or basal ganglia characteristic of Leigh's encephalomyelopathy.

The subject's younger sibling JH also was the product of a fullterm uncomplicated pregnancy and delivery (birth weight 3070 g). He presented with weakness at age 1 yr. Arterial lactate was $3.7 \mathrm{mM}$. A muscle biopsy showed abnormally increased numbers of type 1 fibers, consistent with fiber type disproportion; the mitochondria appeared normal and no abnormal storage material was present. Plasma amino acid analysis showed slightly elevated alanine; urinary organic acids were normal, as were carnitine and biotinidase. He was treated with a ketogenic diet with good response for 6 months; due to increased weakness, the fat content of his diet was gradually increased to $90 \%$ of total energy ( $8 \%$ protein, $2 \%$ carbohydrate). At age 2 yr he was admitted to the University of Minnesota Hospital for severe weakness after a rotavirus infection, with ataxia, ptosis, and ophthalmoplegia. A head CT scan was normal. After intravenous therapy with intralipid (without glucose) and continuous nocturnal feedings, his condition improved. At age $4 \mathrm{yr}$, he remains relatively stable. Blood lactate and pyruvate remain elevated (range 1.9-5.3 and 0.3-0.7 $\mathrm{mM}$, respectively) with a normal ratio. His dietary treatment is supplemented with sodium bicar- 
bonate, $1 \mathrm{mEq} / \mathrm{kg} /$ day, and L-carnitine, $75 \mathrm{mg} / \mathrm{kg} /$ day. He continues to have marked hypotonia, exacerbated by physical or emotional stress, with areflexia and soft, doughy muscles. Cardiac function has remained normal by echocardiogram. Height and weight are at the 90th percentile for age and he is normocephalic. Serial developmental testing shows moderate delay with a developmental quotient of 65-69 and more profound gross motor delay.

\section{RESULTS}

Activity of PDC in lymphocytes and fibroblasts. PDC activity was initially measured in fresh lymphocytes from $\mathrm{CH}$, and was about $7 \%$ of the average activity of controls (Table 1). Lymphocytes from the younger brother, $\mathrm{JH}$, were then assayed and PDC activity was found to be even lower. Surprisingly, when cultured skin fibroblasts from these two boys were assayed, the activity of PDC was normal and displayed normal properties of activation by preincubation with dichloroacetate and inactivation by preincubation with fluoride. Fibroblasts from $\mathrm{CH}$ were reassayed on a separate occasion with virtually identical results. Lymphocytes and fibroblasts were then obtained from other family members. PDC activity was about $35 \%$ of the average of controls in the mother's lymphocytes (in two separate assays), consistent with a heterozygous state. The activity of PDC was normal in her fibroblasts, as was found in her two sons. However, PDC activity was completely normal in both lymphocytes and fibroblasts from the father and sister. To test whether this defect might be inherited in an X-linked manner, lymphocytes were obtained from both maternal grandparents and from the maternal grandmother's mother and sister. PDC activity in these subjects was in the range of $1.4-1.8 \mathrm{nmol} / \mathrm{min} / \mathrm{mg}$ protein, or at least $75 \%$ of the average of controls (Table 1). Therefore, the only family member who was found to express an abnormally low level of PDC activity in lymphocytes was the affected subjects' mother.

Activity of PDC in mitochondria and frozen tissues. When subject $\mathrm{CH}$ died, tissues were obtained at autopsy shortly after death. Mitochondria were prepared immediately from liver and muscle and aliquots of various tissues were frozen. The activity of PDC was assayed in these samples and compared with activities found in similar preparations of mitochondria or frozen tissues obtained from control children who did not have PDC deficiency (Table 2). The activity of PDC in liver and muscle mitochondria from $\mathrm{CH}$ was $3 \%$ and less than $1 \%$, respectively, of the average of controls. PDC activity in homogenized frozen

Table 1. PDC activity in lymphocytes and fibroblasts*

\begin{tabular}{lccccc}
\hline \multirow{2}{*}{ Subject } & \multicolumn{2}{c}{ Lymphocytes } & & \multicolumn{2}{c}{ Fibroblasts } \\
\cline { 2 - 3 } \cline { 5 - 6 } & DCA & Fluoride & & DCA & Fluoride \\
\hline $\mathrm{CH}$ & 0.14 & 0.03 & & 2.01 & 0.66 \\
$\mathrm{JH}$ (brother) & 0.08 & 0.04 & & 4.39 & 0.91 \\
$\mathrm{MH}$ (sister) & 2.06 & 0.26 & & \\
$\mathrm{KH}$ (mother) & 0.67 & 0.12 & & 2.90 & 1.53 \\
TH (father) & 2.14 & 0.32 & & 3.02 & 1.50 \\
Maternal ancestors & & & & \\
$\quad$ Grandmother & 1.49 & 0.43 & & \\
$\quad$ Grandfather & 1.79 & 0.48 & & \\
$\quad$ Great grand- & 1.51 & 0.30 & & \\
$\quad$ mother & & & & \\
$\quad$ Great aunt & 1.45 & 0.25 & & \\
Controls $\dagger$ & & & & \\
$\quad$ Mean \pm SD & $1.9 \pm 0.6$ & $0.5 \pm 0.3$ & & $2.6 \pm 0.9$ & $1.2 \pm 0.6$ \\
Range & $0.9-3.8$ & $0.1-1.6$ & $1.1-6.7$ & $0.1-3.3$ \\
\hline
\end{tabular}

${ }^{*} \mathrm{nmol}{ }^{14} \mathrm{CO}_{2}$ from $\left[1-{ }^{14} \mathrm{C}\right]$ pyruvate $/ \mathrm{min} / \mathrm{mg}$ protein, after activation by preincubation with dichloroacetate (DCA) or inactivation with fluoride.

$\dagger$ Control values for lymphocytes from 67 adults and skin fibroblasts from 48 children.
Table 2. PDC activity in mitochondria and homogenates*

\begin{tabular}{clcccc} 
& & \multirow{2}{*}{ Patient } & \multicolumn{3}{c}{ Controls } \\
\cline { 4 - 6 } Tissue & Preparation & CH & Mean \pm SD & Range & $n$ \\
\hline Liver & Mitochondria & 0.32 & $10.9 \pm 4.7$ & $4.2-18$ & 13 \\
& Homogenate & 0.02 & $1.6 \pm 1.0$ & $0.2-4.6$ & 22 \\
\multirow{2}{*}{ Muscle } & Mitochondria & 0.22 & $77 \pm 25$ & $36-127$ & 9 \\
& Homogenate & 0.01 & $2.5 \pm 1.7$ & $0.9-6.3$ & 15 \\
\multirow{2}{*}{ Heart } & Homogenate & 0.2 & $6.6 \pm 4.3$ & $1.9-16$ & 8 \\
Kidney & Homogenate & 2.5 & $5.0 \pm 2.1$ & $2.7-8.0$ & 5 \\
\hline
\end{tabular}

${ }^{*} \mathrm{nmol} / \mathrm{min} / \mathrm{mg}$ protein after preincubation with dichloroacetate (fresh mitochondria) or without pretreatment (homogenates of frozen tissues).

liver, muscle, and heart was $1-3 \%$ of the average of controls. Kidney, however, had a significant level of PDC activity corresponding to nearly half that found in controls. In separate assays of pieces of frozen kidney the activity varied from 1.8 to 4.2 $\mathrm{nmol} / \mathrm{min} / \mathrm{mg}$ protein, suggesting possible variation within this tissue. The low activity of PDC in homogenized frozen liver was not increased by preincubation with added purified $\mathrm{E}_{1}$ phosphatase, whereas addition of $E_{1}$ phosphatase to liver from a control in the same assay resulted in 4-fold activation. Therefore, the low activity of PDC in tissues from $\mathrm{CH}$ could not be accounted for by lack of $E_{1}$ phosphatase.

Activity of other pyruvate-related enzymes in cells and tissues. The activity of three other mitochondrial enzymes related to metabolism of pyruvate (pyruvate carboxylase, phosphoenolpyruvate carboxykinase, and citrate synthase) were assayed in fibroblasts, liver, and kidney (Table 3). The activities of all three of these enzymes were within the range of controls or higher in the cell and tissue homogenates, indicating that the lack of activity of PDC was a specific abnormality. In liver mitochondria, the activity of these enzymes was only about half the average of controls, indicating that enzyme activities in this mitochondrial preparation were generally somewhat lower than expected.

Activity of PDC components in liver mitochondria and fibroblasts. To determine which component of PDC was defective, partial reactions catalyzed by the three catalytic components of the complex were assayed in fibroblasts and liver mitochondria (Table 4). Assays for these component activities depend on nonphysiological reactions that result in formation or use of nonenzyme-bound intermediates. Relative to activity of the overall complex, the rate of these partial reactions is much less for $E_{1}$ and much greater for $E_{2}$ and $E_{3}$. The activity of $E_{1}$ was absent in liver mitochondria and relatively high in fibroblasts. The activities of $E_{2}$ and $E_{3}$ were about half the average of controls, but just within the control range and consistent with what was found with other enzymes in this preparation of liver mitochondria. The activity of $E_{1}$ was equal to controls in fibroblasts. Therefore, the absence of $E_{1}$ activity in liver mitochondria accounts for the virtual absence of PDC activity.

Western immunoblots of PDC components in tissues and fibroblasts. Solubilized protein extracts of the various frozen tissues were separated by SDS-polyacrylamide gel electrophoresis, immobilized by electrotransfer onto a membrane, and identified by binding of specific antibodies to the various components of PDC (Fig. 1). Compared to a control, neither the $\alpha$-nor $\beta$-subunit of $\mathrm{E}_{1}$ could be detected in liver, muscle, or heart. Significant amounts of $E_{1} \alpha$ and $E_{1} \beta$ were, however, found in kidney, and were present in apparently normal quantity in fibroblasts (Fig. 2). The $E_{2}$ and $E_{3}$ proteins were present in amounts approximately equal to the control in all tissues and fibroblasts. These findings, therefore, are consistent with measurements of PDC and component activities in the various cells and tissues. 
Table 3. Activity of other mitochondrial enzymes related to pyruvate metabolism*

\begin{tabular}{|c|c|c|c|c|c|c|c|}
\hline \multirow[t]{2}{*}{$\begin{array}{c}\text { Type of } \\
\text { specimen }\end{array}$} & \multirow{2}{*}{\begin{tabular}{l}
\multicolumn{1}{c}{ Subject } \\
Patient CH \\
Controls $\dagger$ \\
(Range)
\end{tabular}} & \multicolumn{2}{|c|}{ Pyruvate carboxylase } & \multicolumn{2}{|c|}{$\begin{array}{c}\text { Phosphoenolpyruvate } \\
\text { carboxykinase }\end{array}$} & \multicolumn{2}{|c|}{ Citrate synthase } \\
\hline & & $\begin{array}{l}2.6 \\
1.3 \pm 0.7 \\
(0.4-3.8)\end{array}$ & (49) & $\begin{array}{l}7.0 \\
4.4 \pm 3.2 \\
(0.7-13.8)\end{array}$ & (49) & $\begin{array}{l}28 \\
30 \pm 14 \\
(15-70)\end{array}$ & (33) \\
\hline Liver mitochondria & $\begin{array}{l}\text { Patient } \mathrm{CH} \\
\text { Controls } \dagger \\
\text { (Range) }\end{array}$ & $\begin{array}{l}173 \\
293 \pm 174 \\
(96-692)\end{array}$ & (11) & $\begin{array}{l}180 \\
320 \pm 194 \\
(109-789)\end{array}$ & (11) & $\begin{array}{l}42 \\
141 \pm 45 \\
(71-228)\end{array}$ & (7) \\
\hline Frozen liver & $\begin{array}{l}\text { Patient } \mathrm{CH} \\
\text { Controls }{ }^{\dagger} \\
\text { (Range) }\end{array}$ & $\begin{array}{l}50 \\
40 \pm 26 \\
(5-94)\end{array}$ & $(22)$ & $\begin{array}{l}49 \\
46 \pm 27 \\
(11-119)\end{array}$ & $(22)$ & $\begin{array}{c}32 \\
38 \pm 9 \\
(23-56)\end{array}$ & (18) \\
\hline Frozen kidney & $\begin{array}{l}\text { Patient } \mathrm{CH} \\
\text { Controls } \dagger \\
\text { (Range) }\end{array}$ & $\begin{array}{l}20 \\
6.9 \pm 5.8 \\
(1.8-15)\end{array}$ & (3) & $\begin{array}{l}50 \\
28 \pm 7 \\
(18-32)\end{array}$ & (3) & $\begin{array}{l}72 \\
72 \pm 29 \\
(36-129)\end{array}$ & (6) \\
\hline
\end{tabular}

$* \mathrm{nmol} / \mathrm{min} / \mathrm{mg}$ protein.

$\uparrow$ Control lymphocytes were obtained from normal adults, skin fibroblasts from children, liver mitochondria from biopsies, and frozen liver and kidney samples from biopsies and autopsies. Values shown are means $\pm \mathrm{SD}$, with the number of subjects in parentheses.

Table 4. PDC component activities in skin fibroblasts and liver mitochondria*

\begin{tabular}{|c|c|c|c|c|c|c|}
\hline $\begin{array}{c}\text { Type of } \\
\text { specimen }\end{array}$ & Subject & $\mathrm{E}_{1}$ & $\mathrm{E}_{2}$ & & $E_{3}$ & \\
\hline Fibroblasts & $\begin{array}{l}\text { Patient } \mathrm{CH} \\
\text { Controls } \dagger \\
\text { (Range) }\end{array}$ & $\begin{array}{l}0.13 \\
0.09 \pm 0.03 \\
(0.06-0.10)\end{array}$ & $\begin{array}{l}4.9 \\
2.9 \pm 1.1 \\
(1.3-5.3)\end{array}$ & (13) & $\begin{array}{l}34 \\
39 \pm 18 \\
(15-67)\end{array}$ & (16) \\
\hline $\begin{array}{l}\text { Liver mi- } \\
\text { tochondria }\end{array}$ & $\begin{array}{l}\text { Patient } \mathrm{CH} \\
\text { Controls } \dagger \\
\text { (Range) }\end{array}$ & $\begin{array}{l}<0.01 \\
0.27 \pm 0.08 \text { (3) } \\
(0.19-0.38)\end{array}$ & $\begin{array}{l}32 \\
67 \pm 21 \\
(30-94)\end{array}$ & (6) & $\begin{array}{l}258 \\
517 \pm 107 \\
(351-626)\end{array}$ & (5) \\
\hline
\end{tabular}

$* \mathrm{nmol} / \mathrm{min} / \mathrm{mg}$ protein.

$\dagger$ Mean \pm SD for controls, with the number of subjects shown in parentheses.

\section{DISCUSSION}

These two brothers clearly have a severe systemic deficiency of PDC, which for undetermined reasons is not expressed in their cultured skin fibroblasts. There was very little detectable PDC activity in lymphocytes, or in liver, skeletal muscle, or heart, from the one who died. Antigens for both subunits of $E_{1}$ were virtually undetectable in these same tissues. These are consistent and specific findings, as the activity of other enzymes and antigenicity of other subunits of PDC were normal. The finding of normal PDC activity and normal $E_{1}$ antigens in the fibroblasts was surprising and initially seemed inconsistent. However, PDC activity was also low in lymphocytes from the other brother and normal in his fibroblasts, which had been obtained and cultured at a separate time. Furthermore, PDC activity and $E_{1}$ antigens were present in relatively greater amounts in postmortem kidney than in other tissues, indicating that the variable expression of PDC was not limited to cultured skin fibroblasts. Fibroblasts in kidney might account for this finding. The finding that the mother also had reduced PDC activity in lymphocytes but not in fibroblasts provided additional evidence that these observations were not the result of an artifact or compound series of errors.

Previous descriptions of PDC deficiency have been based almost entirely on observations of activity in cultured fibroblasts. We recently reported another fatal case of profound systemic PDC deficiency in which the activity in fibroblasts was about $30 \%$ of controls whereas the activity in liver and muscle mitochondria was less than $1 \%$ of controls and PDC activity in homogenates of liver, muscle, kidney, heart, and brain was 2 -
$10 \%$ of controls (4). That case was similar to the present family in that amounts of both $\mathrm{E}_{1} \alpha$ and $\mathrm{E}_{1} \beta$ were greatly diminished. An additional fatal case of combined $\mathrm{E}_{1} \alpha$ and $\mathrm{E}_{1} \beta$ deficiency that we investigated also had significant residual PDC activity in fibroblasts (5). Other cases of PDC deficiency that we have tested have had much lower levels of PDC activity in skin fibroblasts, but these individuals have not had a more severe clinical outcome. Similarly, in a series of 30 patients recently reported as PDC deficient, activity in fibroblasts did not correlate well with severity of clinical outcome (3). It is evident from our data that cultured skin fibroblasts do not consistently reflect the level of PDC activity in body tissues. Dependence on fibroblasts alone for diagnosis of this disorder could be misleading. In the present case assay of fibroblasts would have failed to detect the disorder.

Current knowledge of regulation of PDC expression in differentiated cells is insufficient to provide an explanation for the variability that we have observed. There are no established tissue differences in PDC that can be considered evidence for isozymes, but this possibility has not been excluded. Tissue-specific isozymes for one or more PDC subunits could account for our findings. It is also possible that there could be multiple gene copies with identical coding regions for specific PDC subunits that are differentially expressed in various tissues and separately affected by mutation. The finding of normal PDC activity in cultured fibroblasts but not in fresh lymphocytes or most frozen tissues might suggest that something about tissue culture conditions protected PDC, but frozen kidney also showed partial expression of PDC. It is very intriguing that these two brothers and many previously reported cases of PDC deficiency were apparently normal at birth. Assuming that the fetus depends on 
PDC for energy production from glucose oxidation, profound intrauterine PDC deficiency would seem incompatible with fetal survival. More information about expression of PDC will be needed to answer these unexplained observations about development and differentiation.

The mechanism accounting for lack of both the $E_{1} \alpha$ and $E_{1} \beta$ subunits is also unexplained. Two distinct cDNA have been isolated for the two subunits, indicating that they are encoded by separate genes (13-15). Lack of both of these mitochondrial proteins might be attributed to a defect of coordinate transcription of two genes, to a common defect of synthesis of precursor proteins, or to failure of incorporation of the mature proteins into the complex. Alternatively, any mutation causing either or both subunits not to be synthesized or incorporated into the complex could result in the other or both subunits being degraded. Further investigation will be needed to determine the site of the mutation causing this defect and the mechanism of combined subunit deficiency.

We considered the possibility of an X-linked mode of inheritance in this disorder because these two brothers and four other similarly affected patients in whom we have found absence of both $\mathrm{E}_{1}$ subunits were all males. The finding that the mother, but not the father, has reduced PDC activity in her lymphocytes appears consistent with this hypothesis. However, the maternal grandmother and great grandmother did not show evidence of reduced lymphocyte PDC activity. Two interpretations are pos-

\section{LIVER KIDNEY MUSCLE HEART

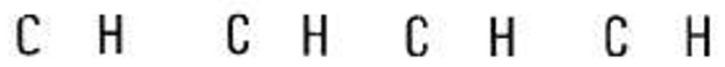
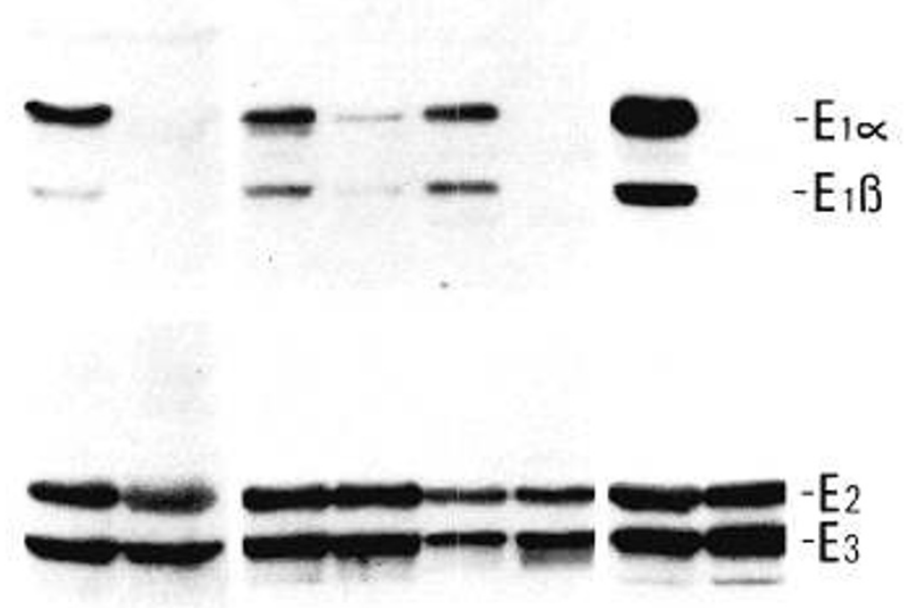
zen tissues obtained postmortem. Comparison of immunoreactivity of the catalytic components of PDC in tissues from the index case $(H)$ and from a similar age control subject $(C)$, also obtained soon after death. Extracts of postmortem tissues ( $0.4 \mathrm{mg}$ protein/sample) were separated by electrophoresis, transblotted, and exposed to either anti- $E_{1}$ sera (upper panels) or to a mixture of anti- $\mathrm{E}_{2}$ and anti- $\mathrm{E}_{3}$ sera (lower panels). As identified all four of these antigens were detected in tissues from the control. $E_{1} \alpha$ and $E_{1} \beta$ are barely detectable in liver, muscle, and heart from the patient, but both are present in the kidney.

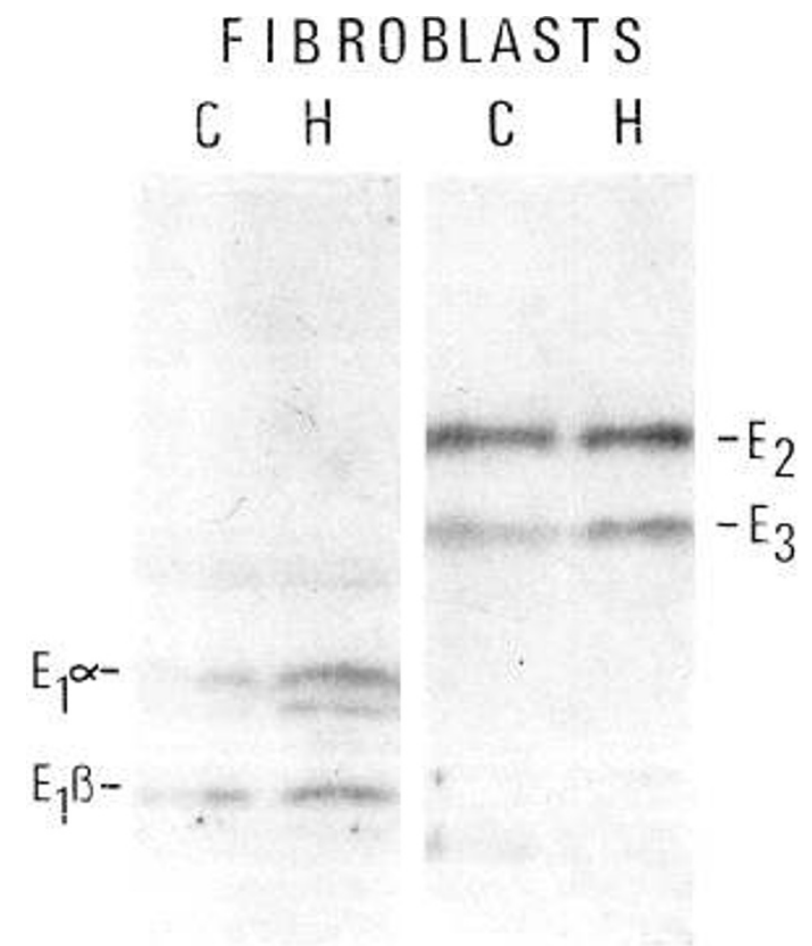

Fig. 2. Western immunoblot of PDC components in fibroblasts. Extracts of cultured skin fibroblasts from the index patient $(H)$ and an agematched control $(C)$ ( $0.4 \mathrm{mg}$ protein/lane) were electrophoresed, transblotted, and developed with anti- $\mathrm{E}_{1}$ sera (left panel) or with anti- $\mathrm{E}_{2}$ and anti- $\mathrm{E}_{3}$ sera (right panel). All four antigens are present in approximately equal amounts in fibroblasts from the patient and control.

sible. One is that the maternal ancestors were heterozygous for the defect but did not express reduced activity, perhaps due to altered distribution of their inactivated X-chromosomes. Another possibility is that the is defect is the result of a mutation in the germ cell line from which the mother was derived. Further investigation of families of patients with combined $E_{1} \alpha$ and $E_{1} \beta$ deficiency is necessary to determine the mode of inheritance.

Experience with therapy of these two brothers with PDC deficiency confirmed earlier observations of the clinical benefit of a high fat, low carbohydrate diet (16). Use of an extremely high fat diet (90\% of energy) appeared to be beneficial. Although not systematically evaluated, it is probable that minimizing the intake of carbohydrate would facilitate ketosis. The finding in $\mathrm{CH}$ of low plasma carnitine and mild, transient fatty infiltration of muscle after use of a very high fat diet suggests the possibility that carnitine supplementation may be useful adjunctive therapy, but this also requires further investigation. However, two other agents that are frequently used in clinical management of PDC deficiency, thiamin and dichloroacetate, were of no apparent benefit in the case of $\mathrm{CH}$; there is no theoretical reason to expect either agent to be effective in the absence of $E_{1}$.

Finally, it should be noted that the neuropathological findings in this case did not include the characteristic subacute focal lesions described in Leigh's necrotizing encephalomyelopathy (17). This is in contrast to two other cases of combined deficiency of $E_{1}$ that we investigated $(4,5)$. Other investigators have reported an association of PDC deficiency with Leigh's disease, but this has not been a consistent finding (18-21). The neuropathological findings of Leigh's disease have also been documented in patients with cytochrome $c$ oxidase deficiency (22). However, in contrast to cytochrome $c$ oxidase deficiency, PDC deficiency typically is not associated with significant pathological changes in skeletal or cardiac muscle, as was confirmed in these brothers. The biochemical requirements for development of these neuropathological findings remain ill defined. Differential expression of 
PDC deficiency in various tissues or cell types within the brain could play a role in development of variable pathological findings, or variation may be related to other environmental factors.

Until better understanding is achieved of the basis for biochemical and pathological heterogeneity of various forms of PDC deficiency, diagnostic enzyme activity and immunological assays should be performed in more than one cell type and tissue whenever possible.

Acknowledgments. The authors are grateful to Drs. Mendel Tuchman and Charles Hoppel for preparation of mitochondria from the patient and controls, respectively, to Dr. Thomas Roche for providing $E_{1}$ phosphatase, to Dr. Lester Reed for providing purified PDC components, to Cindy Raefsky and Donna Carothers for preparation of anti- $E_{1}$, anti- $E_{2}$, and anti- $E_{3}$ sera, and to Drs. Arthur Zinn and Isaiah Wexler for helpful comments concerning preparation of the manuscript.

\section{REFERENCES}

1. Blass JP 1983 Inborn errors of pyruvate metabolism. In: Stanbury JB, Wyngaarden JB, Fredrickson DS, Goldstein JL, Brown MS, (eds) The Metabolic Basis of Inherited Disease, 5th ed. McGraw-Hill, New York, pp 193-203

2. Robinson BH, Taylor J, Sherwood WG 1980 The genetic heterogeneity of lactic acidosis: Occurrence of recognizable inborn errors of metabolism in a pediatric population with lactic acidosis. Pediatr Res 14:956-962

3. Robinson BH, MacMillan HM, Petrova-Benedict R, Sherwood WG 1987 Variable clinical presentation in patients with defective $E_{1}$ component of the pyruvate dehydrogenase complex. J Pediatr 111:525-533

4. Kerr DS, Ho L, Berlin CM, LaNoue KF, Towfighi J, Hoppel CL, Lusk MM, Gondek CM, Patel MS 1987 Systemic deficiency of the first component of the pyruvate dehydrogenase complex. Pediatr Res 22:312-318

5. Ho L, Hu C-WC, Packman S, Patel MS 1986 Deficiency of the pyruvate dehydrogenase component in pyruvate dehydrogenase complex-deficient human fibroblasts: Immunological identification. J Clin Invest 78:844-847

6. Fotino M, Merson EJ, Allen FH 1971 Micromethod for rapid separation of lymphocytes from peripheral blood. Ann Clin Lab Sci 1:131-133

7. Schneider WC, Hogeboom GH 1950 Intracellular distribution of enzymes. V. Further studies on the distribution of cytochrome $c$ in rat liver homogenates.
J Biol Chem 183:123-128

8. Sheu K-FR, Hu C-WC, Utter MF 1981 Pyruvate dehydrogenase activity in normal and deficient fibroblasts. J Clin Invest 67:1463-1471

9. Chuang DT, Niu W-L, Cox R 1984 Activities of branched-chain 2-oxo acid dehydrogenase and its components in skin fibroblasts from normal and classical maple syrup urine disease subjects. Biochem J 200:59-67

10. Atkin BM, Utter MF, Weinberg MD 1979 Pyruvate carboxylase and phosphoenol-pyruvate carboxykinase activity in leukocytes and fibroblasts from a patient with pyruvate carboxylase deficiency. Pediatr Res 13:38-43

11. Lowry OH, Rosebrough NJ, Farr AL, Randall RJ 1951 Protein measurement with Folin phenol reagent. J Biol Chem 193:265-276

12. Laemmli UK 1970 Cleavage of structural proteins during assembly of the head of bacteriophage T4. Nature 227:680-685

13. Dahl HM, Hunt SM, Hutchinson WM, Brown GK 1987 The human pyruvate dehydrogenase complex. Isolation of cDNA clones for the $E_{1} \alpha$ subunit, sequence analysis, and characterization of the mRNA. J Biol Chem 262:7398-7403

14. Koike K, Ohta S, Urata Y, Kagawa Y, Koike M 1988 Cloning and sequencing of cDNAs encoding $\alpha$ and $\beta$ subunit of human pyruvate dehydrogenase. Proc Natl Acad Sci USA 85:41-45

15. Ho L, Javed AA, Pepin RA, Thekkumkara TJ, Raefsky C, Mole JE, Caliendo AM, Kwon MS, Kerr DS, and Patel MS 1988 Identification of a cDNA clone for the $\beta$-subunit of the human pyruvate dehydrogenase complex. Biochem Biophys Res Commun 150:904-908

16. Falk RE, Cederbaum SD, Blass JP, Gibson GE, Pieter Kark RA, Carrel RE 1976 Ketogenic diet in the management of pyruvate dehydrogenase deficiency. Pediatrics 58:713-721

17. Dayan AD, Ockenden BG, Crome L 1970 Necrotizing encephalomyelopathy of Leigh. Neuropathological findings in 8 cases. Arch Dis Child 45:39-48

18. DeVivo DC, Haymond MW, Obert KA, Nelson JS, Pagliara AS 1978 Defective activation of the pyruvate dehydrogenase complex deficiency in subacute necrotizing encephalomyelopathy (Leigh disease). Ann Neurol 6:483-494

19. Ohtake M, Takada G, Miyabayashi S, Arai N, Tada K, and Morinaga S 1982 Pyruvate decarboxylase deficiency in a patient with Leigh's encephalomyelopathy. Tohoku J Exp Med 137:379-386

20. Kretzschmar HA, DeArmond SJ, Koch TK, Patel MS, Newth CJL, Schmidt KA, Packman S 1986 Pyruvate dehydrogenase complex deficiency as the etiology of Leigh's disease. Pediatrics 79:370-373

21. Toshima K, Kuroda Y, Hashimoto T, Ito M, Watanabe T, Miyao M, Ii K 1982 Enzymological studies and therapy of Leigh's disease associated with pyruvate decarboxylase deficiency. Pediatr Res 16:430-435

22. DiMauro S, Servidei S, Zeviani M, DiRocco M, DeVivo DC, DiDonato S, Uziel G, Berry K, Hoganson G, Johnsen SD, Johnson PC 1987 Cytochrome $c$ oxidase deficiency in Leigh syndrome. Ann Neurol 22:498-506 